\title{
Paraneoplastic Urticarial Vasculitis and Recurrence of Prostatic Adenocarcinoma
}

\author{
Marsaudon $\mathrm{E}^{* 1}$, Ksiyer $\mathrm{S}^{1}$, Louarn $\mathrm{A}^{2}$ and Ilardo $\mathrm{C}^{2}$ \\ ${ }^{1}$ Medical Doctor, Internal Medicine Service, Hospital Alphonse Guerin, Ploermel, France \\ ${ }^{2}$ Primary Care Resident, Internal Medicine Service, Hospital Alphonse Guerin, Ploermel, France
}

${ }^{*}$ Corresponding author: Marsaudon E, Internal medicine service, Hospital Alphonse Guerin, 7 rue du roi Arthur, 56800 Ploermel, France, Tel: +33297732416, E-mail: marsaudon.eric@orange.fr

Citation: Marsaudon E, Ksiyer S, Louarn A, Ilardo C (2018) Paraneoplastic Urticarial Vasculitis and Recurrence of Prostatic Adenocarcinoma. J Case Rep Stud 6(5): 502. doi: 10.15744/2348-9820.6.502

Received Date: August 03, 2018 Accepted Date: October 29, 2018 Published Date: October 31, 2018

\begin{abstract}
Chronic urticaria is a common condition but its etiology can sometimes be serious. A variety of causes has been reported to induce urticaria, like food, infections, drugs or environmental factors. Although an association between chronic urticarial and malignancy has been occasionally reported, such association remains controversial because it's difficult to demonstrate it's not just coincidental. However, various cancers have been described in connection with this skin pathology such as thyroid, pulmonary or renal carcinoma. In all of these cases, treatment of the tumor led to prompt resolution of the urticarial lesions, thus suggesting a pathogenetic relationship between the two. We report the case of a man treated for several months without success for chronic urticaria whose treatment of the recurrence of his prostate cancer has removed the skin lesions.
\end{abstract}

Key Words: Paraneoplastic Urticarial; Vasculitis; Prostatic Adenocarcinoma

\section{Introduction}

Chronic urticarial defined by skin lesions evolving for more than 6 weeks, can persist for months or years before finding an etiology that can remain unknown in $50 \%$ of cases. Many causes of urticaria have been reported, as alimentary, infections, drugs, dysthyroidism or autoimmune disease. Until now, 41 cases of malignancies have been associated with urticaria and reported with thyroid carcinomas, seminoma, astrocytoma, lymphoreticular system malignancies, lung cancer or renal carcinoma (Table 1). Description with prostate cancer is rare, justifying our case report regarding a man whose skin lesion testified the recurrence of his cancer.

\begin{tabular}{|c|c|}
\hline Cancer localization & Number of chronic urticaria described \\
\hline Myeloma & 8 \\
\hline Lymphoma & 8 \\
\hline Lung & 6 \\
\hline Thyroid & 5 \\
\hline Leukemia & 3 \\
\hline Kidney & 2 \\
\hline Gut & 2 \\
\hline Testicle & 2 \\
\hline Ovary & 1 \\
\hline Breast & 1 \\
\hline Gastric carcinoid & 1 \\
\hline Brain & 1 \\
\hline Prostate & 1 \\
\hline
\end{tabular}

\section{Case Report}

A 84-year-old man was admitted for weakness, anemia and chronic urticarial plaques treated for 9 months with corticosteroids 
(first $0.5 \mathrm{mg} / \mathrm{kg} /$ day during 6 month then $1 \mathrm{mg} / \mathrm{kg} /$ day) and antihistamines (dexchlorphéniramine then levocetirizne). He was arrhythmic, carried a valvular heart disease and benefited from coronary angioplasty for a myocardial infarction. In 2003, he underwent surgery for a prostatic adenocarcinoma classified as pT3NxM1 and treated with anti-androgenic. Treatment was stopped in 2010 while the PSA level was $0.09 \mathrm{ng} / \mathrm{ml}$.

Clinical examination is satisfactory except a $38^{\circ} \mathrm{C}$ fever, a systolic murmur and resting dyspnea. The urticarial lesions are slightly pruriginous and spread throughout the body, trunk and 4 limbs (Figure 1). Biological investigations found hemoglobin at 8.7 $\mathrm{g} / \mathrm{l}, \mathrm{CRP}$ at $180 \mathrm{mg} / \mathrm{l}, \mathrm{PSA}$ at $36.29 \mathrm{ng} / \mathrm{l}$. Ionic balance is normal while clearance of creatinine is at $73 \mathrm{ml} / \mathrm{min}$. Thyroid blood control, complement C3 and C4, C1 inhibitor antigenic level, antithyroid autoantibodies, antinuclear antibodies, cryoglobulin, rheumatoid factor, serum immunoglobulins level, circulating immune complexes, stool screening for blood parasites and yeast, serum electrophoresis, total immunoglobulin E are all normal.

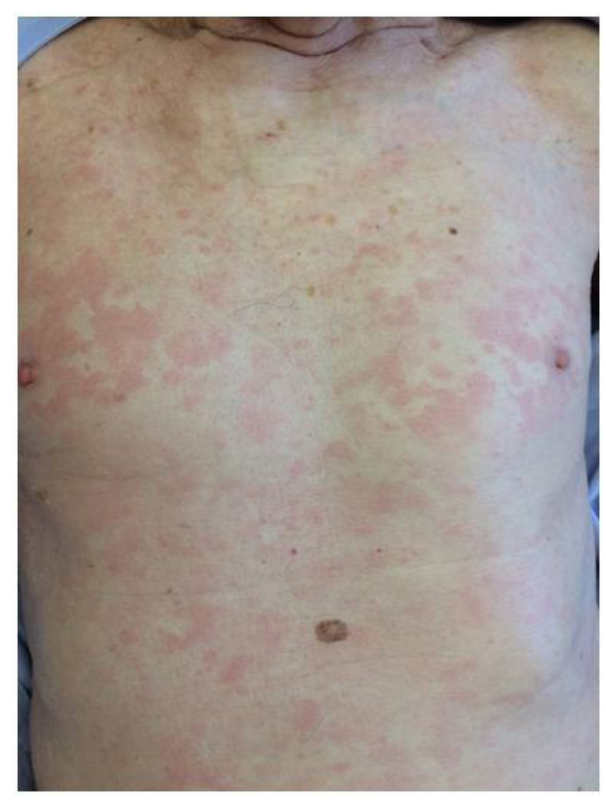

Figure 1: chronic urticarial vasculitis

Endoscopy finds gastric atrophy and colonoscopy discovers sigmoid diverticulosis. The myelogram is normal. The chest CT scan shows a bilateral pleural effusion of low abundance and interstitial pneumopathy of the right lower lobe. Bronchial fibroscopy and staged biopsies are reassuring. The abdominal CT revealed multiple parenchymal hepatic nodules (the largest was $17 \mathrm{~mm}$ ) with intraperitoneal effusion and infiltration of superior mesenteric fat. Cardiac ultrasonography exclude endocarditis but shows dilated cardiomyopathy with an ejection fraction of $28 \%$. Scintigraphy shows diffuse bone metastases in the pelvis and skin biopsy find pericapillary inflammatory infiltrate without vascular necrosis confirming leukocytoplasic vasculitis and excluding mastocytosis.

The patient receives antibiotic treatment by ceftriaxone ( $1 \mathrm{~g} /$ day during 7 days) improving the respiratory infection and normalizing his CRP. In a second time treatment both oral bicalutamide $(50 \mathrm{mg} /$ day) and leuprorelin injection (subcutaneous implant $3.6 \mathrm{mg}$ every 28 days) is proposed for its prostatic adenocarcinoma. Two months later, all the skin lesions disappeared (Figure 2 ).

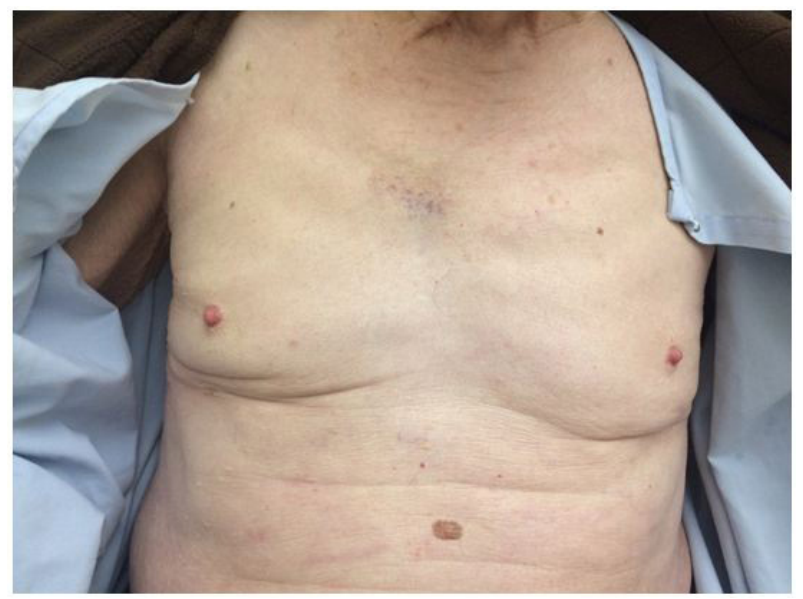

Figure 2: after 2 months of anti-androgenic treatment 


\section{Discussion and Conclusion}

Paraneoplastic dermatoses are not metastatic spreads but accompany the natural history of cancers for about 8\% of them [1]. Usually disappearing during curative treatment and reappearing at relapses, they are expressed by variable clinical signs: acanthosis nigricans, Bazex acrokeratosis, palmar fasciitis, lanuginous hypertrichosis, erythema gyratum repens, paraneoplastic pemphigus dermatomyositis [2].

Chronic urticaria is a rare form of these cutaneous manifestations whose paraneoplastic character has been described with lymphoma, thyroid, colic, mammary, leukemic, renal, ovarian, pulmonary and testicular cancers [3-11].

Its link with prostatic cancer is very rare, the international literature reporting so far only one case allowing as in our presentation, to discover the disease [12]. It was a 63-year-old patient suffering from 6 months of chronic urticaria whose treatment with both oral antihistamine and systemic and topical corticosteroid therapies were ineffective. Prostate biopsies confirming a prostate adenocarcinoma, he underwent a radical prostatectomy and after a few weeks, urticaria spontaneously disappeared. In the two years following prostatectomy no new episode of urticaria reappeared.

Currently etiopathogenic mechanisms responsible for this paraneoplastic vasculitis aren't still fully understood although the explanation is probably based on vascular hypersensitivity to cytokines produced by neoplastic cells. For practice however, notice that the main specific of this cutaneous reaction is a weakly pruriginous nature and a poor sensitivity to the corticosteroid/ antihistaminic association usually proposed in front of the appearance of urticarial plaques.

\section{Author's Contribution}

All the authors participated in the care of the patient, and in the realization of the article. All authors have read and approved the final version of the manuscript.

\section{References}

1. Pelosof LC, Gerber DE, (2010) Paraneoplastic syndromes: an approach to diagnosis and treatment. Mayo Clin Proc 85: 838-54.

2. Lasek A, Lebas D, Modiano P (2012) Les dermatoses paranéoplasiques. Réal Thérap Dermato-Vénérologie 214: 38 -43

3. Napolitano M, Patruno C (2018) Chronic urticaria can be caused by cancer and resolves with its cure. Allergy 73: 1750-1.

4. Kartal O, Abdullah B, Ramazan E, Mustafa G, Zafer C, et al. (2012) Acute urticaria associated with thyroid papillary carcinoma: a case report. Ann Dermatol 24: 453-4.

5. Lewis JE (1990) Urticarial vasculitis occurring in association with visceral malignancy. Acta Derm Venereol 70: 345-7.

6. O'Donnell E1, Havyer R (2014) Breast malignancy masquerading under the cloak of acute urticaria. BMJ Case Rep 29: 2014.

7. Kassim JM, Igali L, Levell NJ (2015) A 14-year paraneoplastic rash: urticarial vasculitis and dermal binding bullous pemphigoid secondary to chronic lymphocytic leukaemia. Clin Exp Dermatol 40: 391-4.

8. Ducarme G, Rey D, Bryckaert PE, Reguiai Z, Bernard P, et al. (2003) Vasculite urticarienne paranéoplasique et carcinome rénal. Prog Urol 13: 495-7

9. Reinhold U, Bruske T, Schupp G (1996) Paraneoplastic urticaria in a patient with ovarian carcinoma. J Am Acad Dermatol 35: 988-9.

10. Greiner D, Schofer H, Boehncke WH (2002) Urticaria associated with a small cell carcinoma of the lung. Cutis 69: 49-50.

11. Sprossmann A, Müller RP (1994) Urticaria-vasculitis syndrome in metastatic malignant testicular teratoma. Hautarzt 45: 871-4.

12. Baroni A, Faccenda F, Russo T, Piccolo V (2012) Figurate paraneoplastic urticaria and prostate cancer. Ann Dermatol 24: 366-7. 